\title{
Uma análise sociolinguística do fenômeno de contato de línguas de code-blending no par linguístico Libras-português
}

\author{
Sabine Gorovitz ${ }^{1}$ \\ Departamento de Línguas Estrangeiras e tradução, Universidade de Brasília, Brasil
}

Leydiane Ribeiro Duarte ${ }^{2}$

Programa de Pós-graduação em Estudos da Tradução - Postrad, Universidade de Brasília, Brasil

Resumo: Analisam-se aqui ocorrências do fenômeno de code-blending no par linguístico Libras e Português, assentando-se em pressupostos da sociolinguística que sugerem que a fala, além de carregar marcas topográficas e diastráticas, também reflete situações de interação e características sócio-demográficas dos falantes. Partindo desse princípio basilar, apresentamos uma descrição preliminar do fenômeno em situações de produções linguísticas espontâneas extraídas de vídeos de acesso público do YouTube e do Facebook. Depreende-se dessa análise preliminar, a partir do cruzamento dos dados linguísticos e dos metadados obtidos on-line e passíveis de sistematização, que ocorrem variedades do fenômeno de acordo com as situações sociolinguísticas de interação, que ensejam gêneros discursivos distintos, e com o perfil sociolinguístico dos falantes, em parte configurado pelo processo de aquisição das línguas.

Palavras-chave: Code-blending; Contatos de línguas; Sociolinguística; Línguas minoritárias.

Abstract: We analyse occurrences of the phenomenon of code-blending in the linguistic pair Libras and Portuguese, based on sociolinguistic assumptions that suggest that speech, besides carrying topographic and diastratographic marks, also reflects situations of interaction and socio-demographic characteristics of speakers. Based on this principle, we present a preliminary description of the phenomenon in situations of spontaneous linguistic productions extracted from publicly accessible videos from Youtube and Facebook. From this preliminary analysis, it can be seen that, from the crossing of linguistic data and metadata obtained online and capable of being systematized, varieties of the phenomenon occur according to the sociolinguistic situations of interaction, which give rise to distinct discursive genres, and to the sociolinguistic profile of the speakers, partly configured by the process of language acquisition.

Keywords: Code-blending; Language contacts; Sociolinguistics; Minority languages.

\footnotetext{
${ }^{1}$ Doutora em Sociolinguística - Université Paris Descartes - Sorbonne; Pós-doutorado pelo SEDYL-CELIA - CNRS (Paris). Orcid: https://orcid.org/0000-0001-5148-7785. E-mail: sabinegz@unb.br/sabinegz@gmail.com.

2 Mestra em Estudos da Tradução - Universidade de Brasília. Orcid: https://orcid.org/0000-0002-0469-3196. E-mail: leydiane.ufg@gmail.com.
} 


\section{Introdução}

O code-blending constitui um fenômeno particular de contato linguístico em que duas línguas de modalidades distintas são produzidas simultaneamente, tratando-se nesse trabalho do par Libras e português. Geralmente, o fenômeno tem sido apreendido pelo viés de aquisição de linguagem, enquanto característico de bilíngues bimodais. De acordo com essas pesquisas, os maiores produtores de code-blending seriam os CoDAs ${ }^{3}$ (QUADROS, 2012; 2013; 2016; 2017). Outros trabalhos também revelam que a situação de interpretação português para Libras favorece a produção do fenômeno, que tende a se manifestar enquanto estratégia de tradução (RODRIGUES, 2013).

Distinguindo-se desses estudos, este trabalho investiga o fenômeno a partir de uma perspectiva sociolinguística, enquanto contato de línguas em um mesmo falante, em situações de interação específicas, partindo de uma indagação central: Quais fatores extralinguísticos se correlacionam com as variedades de code-blending produzidas por ouvintes e Surdos em situações sociolinguísticas específicas?

Para ensejar alguns elementos de resposta, conduziu-se uma análise preliminar de ocorrências do fenômeno a partir de um corpus restrito, constituído de vídeos em que os participantes foram filmados produzindo code-blending em situações espontâneas. Após a transcrição dos enunciados em português e em Libras, por meio do sistema de Glosas ${ }^{4}$, procedeu-se à análise qualitativa dos dados. Foram cruzados três tipos de variáveis: linguísticas (tipos de code-blending); perfis dos falantes, com base em metadados obtidos on-line; e fatores extralinguísticos relacionados às situações específicas nas quais as interações foram produzidas e os gêneros discursivos que delas emergem: interpretação profissional, palestra, entrevista e propaganda política.

Sugere-se também, com base em pesquisas anteriores (PERLIN, 1998), que o perfil sociolinguístico remete a tipos de identidade influenciados por processos de aquisição linguística dos falantes pertencentes à comunidade surda bilíngue (Surdos e CoDAs): a "identidade de transição", que se refere a falantes Surdos que adquiriram a Libras posteriormente à sua oralização em português, passando então a transitar entre o mundo ouvinte e a comunidade Surda; a "identidade flutuante", característica do sujeito Surdo que adquiriu a Libras também posteriormente, e "flutua" entre o mundo ouvinte e o Surdo, porém não tendo consciência de sua surdez e não se identificando com a comunidade Surda; e a "identidade híbrida", em que o sujeito se sente pertencer a ambas as comunidades, ouvinte e Surda, tendo adquirido ambas as línguas simultaneamente como línguas primeiras, sendo, de acordo com Perlin, a que mais favorece a produção do fenômeno de codeblending.

\footnotetext{
${ }^{3}$ CoDAs é a sigla para "Children of Deaf Adults", ou seja, criança ouvinte com pais Surdos (STREIECHEN; KRAUSE-LEMKE, 2013).

4 "Glosa é uma palavra que traduz aproximadamente o significado de outro signo, neste caso, os sinais da Libras. A Glosa Libras - Português é representada sempre com a escrita em maiúscula entre outras regras descritas por Felipe (2007)" (SANTIAGO, 2012, p. 39).
} 
De modo a apreender o code-blending para além das ocorrências do corpus, buscouse partir do contexto sociolinguístico em que o fenômeno se manifesta, inicialmente apresentando uma breve distinção, central para a comunidade Surda, entre o code-blending e o português sinalizado. Em seguida, descreveu-se o contexto social em que a comunidade Surda evolui, e que afeta diretamente a maneira como concebem e produzem a Libras. São apresentados estudos anteriores sobre o code-blending e conceitos da sociolinguística que justificam sua apreensão enquanto fenômeno sistematizável. Partindo desses trabalhos anteriores, colocam-se em perspectiva as situações sociolinguísticas de interação e os perfis sociolinguísticos dos falantes, de modo a caracterizar os dados analisados.

Ressalta-se que o trabalho constitui uma descrição preliminar de ocorrências do fenômeno, com base em uma amostragem inicial limitada. Possibilitou, entretanto, levantar algumas hipóteses a serem convalidadas por estudos posteriores mais aprofundados, com base em uma quantidade satisfatória de fatores extralinguísticos, referentes tanto ao perfil dos falantes, quanto à variedade das situações sociolinguísticas de interação.

Buscou-se, entretanto, iniciar uma discussão que possa contribuir com a área da Sociolinguística e dos estudos da interpretação em sua tentativa de descrever, sistematizar e interpretar fenômenos de contato de línguas de acordo com determinadas situações, evidenciando a diversidade linguística que caracteriza as práticas cotidianas.

Pautando-se nesse tipo de pesquisa, busca-se reconhecer e valorizar o multilinguismo característico da maioria dos falantes, ainda que se trate de variedades do que é considerado uma mesma língua. Assim, a partir desse reconhecimento, políticas linguísticas inclusivas têm sido lentamente elaboradas e implementadas, de modo a garantir os direitos linguísticos e o acesso a espaços de fala e de atuação de minorias linguísticas, como os Surdos.

\section{Contexto de pesquisa e embasamento teórico-metodológico}

\section{Code-blending não é Comunicação Total}

Parte-se do pressuposto de que a situação sociolinguística da comunidade Surda foi paulatinamente forjada pela história da Educação de Surdos. Nascimento (2006) apresenta esse histórico, atrelando-o ao próprio processo de evolução social do sujeito Surdo. A autora esclarece que os Surdos e seus próximos, pais ou educadores, nunca chegaram a um consenso com relação à questão da sua aquisição linguística. A divisão ocorre entre "aquele que defende o ensino da língua oral para os Surdos como única forma de inseri-los na comunidade ouvinte" e "aquele que defende a língua de sinais, própria da comunidade Surda, como meio linguístico pelo qual se deve desenvolver sua educação" (p. 256). Goldfeld explica que a discussão ganha visibilidade no século XVIII, no Congresso Internacional de Educadores de Surdos, em Milão, em 1880: "naquele momento acreditava-se que o Surdo poderia desenvolver-se como os ouvintes aprendendo a língua oral" (1997, p. 31). Esse acontecimento, que repercutiu mundialmente, representou um retrocesso significativo com 
relação às propostas anteriores de Educação de Surdos. Foi preciso esperar a década de 1960, com a publicação dos estudos de William Stokoe a respeito das Línguas de Sinais (1960), que mostra que a ASL (American Sign Language) apresenta uma estrutura gramatical com características linguísticas tão específicas e complexas quanto as línguas orais, para que as línguas de sinais fossem reconhecidas enquanto língua.

Além disso, o fracasso do ensino de Surdos por meio do método oralista dá margem à implementação de novas metodologias, em especial a da Comunicação Total (CT), inaugurada em 1968. Essa abordagem, paradigmática na educação de Surdos, se assenta na hipótese de que "somente o aprendizado da língua oralizável não assegura o pleno desenvolvimento da criança Surda" (GOLDFELD, 1997, p. 39). Embora a CT também se preocupasse com a aprendizagem da língua oral, entendia que eram necessários múltiplos recursos visuoespaciais e manuais como facilitadores da comunicação: a datilologia, também chamada de alfabeto manual (representação manual das letras do alfabeto), o cued-speech (sinais manuais que representam os sons da língua portuguesa), o português sinalizado (língua artificial que utiliza o léxico da língua de sinais com a estrutura sintática do português e alguns sinais inventados, para representar estruturas gramaticais do português que não existem na língua de sinais) e o pidgin (simplificação da gramática de duas línguas em contato, no caso, o português e a língua de sinais) (GOLDFELD, 1997, p. 38-40). Tais recursos foram, entretanto, implementados com o objetivo de auxiliar os Surdos no aprendizado da língua oral. Goldfeld (1997) relata que, nas décadas de 70 e 80, várias pesquisas surgiram para comprovar a eficácia do novo método. Todavia, os estudos mostraram também que os Surdos apresentavam "sérias dificuldades em expressar sentimentos e ideias e comunicar-se em contextos extraescolares" (Goldfeld, 1997, p. 6). O problema, segundo a autora, dava-se na concepção de língua oferecida aos alunos: "os sinais ocupam um lugar meramente acessório de auxiliar da fala, não havendo espaço para seu desenvolvimento" e, portanto, os Surdos não "aprendem a compreender os sinais como uma verdadeira língua, e desse uso não decorre um efetivo desenvolvimento linguístico" (1998, p. 6). O resultado é que, com a $\mathrm{CT}$, os Surdos não adquiriam nem a Língua de Sinais nem a Língua Oral à qual eram submetidos.

Distinguindo-o da CT, Sousa e Quadros (2012, p. 329) definem o code-blending como um fenômeno linguístico que ocorre quando "duas línguas são produzidas simultaneamente". Ou seja, é um fenômeno de bilinguismo bimodal, associado a uma competência em uma língua oral e em uma língua de sinais. A ocorrência do fenômeno é possibilitada pelo fato de que os dois canais articulatórios do interlocutor - a fala oralizada e o corpo - estão disponíveis. Com relação à distinção estrutural entre as línguas, Brito (1995) explica que "a diferença entre a LS e a LO é a caracterização fonológica das línguas; enquanto as LS têm padrões de simultaneidade, as LO são lineares" (1995, p. 36). Acrescenta que não se trata de um método que visa ao ensino de uma língua, mas de um fenômeno natural característico de falantes bilíngues bimodais. Partindo de tais premissas, apreendese o processo como envolvendo duas línguas de modalidades distintas, a chamada "bimodalidade", que ocorre quando o falante adquiriu as estruturas de ambas as línguas 
envolvidas.

Quadros (2013, p. 381) destaca também que a bimodalidade não pode ser confundida com o português sinalizado, referindo-se exclusivamente à condição de produção de duas línguas que se apresentam em modalidades distintas. Argumenta que as estruturas sintáticas da Libras são marcadas por elementos de indexação e pelo uso de classificadores. Além disso, a topicalização das sentenças são elementos exclusivos das línguas de sinais que não caracterizam fenômenos linguísticos como o português sinalizado. Esse seria preferencialmente definido como uma mistura de línguas caracterizada por decalques, produzidos a partir da influência de uma língua oral sobre uma língua de sinais, no caso, o português sobre a Libras. Por sua vez, os itens constitutivos da gramaticalidade do português se manifestam na língua de sinais por meio da invenção de algum sinal ou da datilologia, o que produz sentenças agramaticais em Libras.

Consideradas as diferenças entre $\mathrm{CT}$, português sinalizado e code-blending, esclarece-se que esse último está sendo analisado sob a prerrogativa da valorização da Libras, interpretado como um recurso linguístico frente a uma necessidade social e não como suporte ao aprendizado de outra língua. Para tanto, sugere-se que variedades de code-blending são produzidas de acordo com situações sociolinguísticas variadas e perfis de falantes distintos, a saber, CoDAs, Surdos oralizados, Ouvintes que já adquiriram fluência em Libras como L2.

\section{Fundamentação teórico-metodológica}

Como foi indicado, a presente análise respalda-se em trabalhos anteriores acerca do fenômeno de code-blending, assentando-se paralelamente em pressupostos basilares da sociolinguística segundos os quais as práticas linguísticas, além de carregar marcas topográficas ou diastráticas, também refletem particularidades de situações sociolinguísticas de interação, assim como características sociais e identitárias dos falantes. Inspirou-se aqui nos trabalhos de Bortoni-Ricardo (2017), que explica que a interação humana constitui o principal fomento dos papéis sociais, obedecendo a princípios de coerência interna das relações interpessoais (p. 148). Nesse sentido, acredita-se aqui que o code-blending ocorra conforme o tipo de interação e o contexto envolvido, ou seja, de acordo com as características estruturais do evento (gêneros discursivos, papéis sociais, exercício e negociação de poder etc.).

Os primeiros trabalhos envolvendo o code-blending objetivavam compreender a aquisição simultânea de duas línguas por CoDAs, buscando inferir como esse processo influenciaria a vida adulta do sujeito e quais mecanismos estavam envolvidos em uma produção bilíngue bimodal. Partindo dessa perspectiva, Petitto (2001) estudou dois grupos de crianças bilíngues, o primeiro, de falantes de Língua de Sinais Francesa e francês oral, e o segundo, de inglês oral e francês oral. A pesquisa visava desmistificar a crença de que a exposição precoce a dois idiomas causaria atraso linguístico. A autora contraria tais pressupostos, não tendo constatado em seu estudo atraso cognitivo nem linguístico algum 
na aquisição das línguas pelas crianças. O estudo revela ainda que, enquanto crianças bilíngues unimodais (inglês e francês orais) produziam code-switching - definido como alternância de línguas, as crianças bilíngues multimodais (Língua de Sinais francesa e francês oral) produziam preferencialmente code-blending.

O pioneirismo nos estudos de bilíngues bimodais também se expressa nos trabalhos de Emmorey et al. (2008) que constituem uma importante contribuição, ao investigar as práticas linguísticas de CoDAs tendo adquirido simultaneamente uma língua de sinais (ASL) em casa com os pais e o inglês com a comunidade. O estudo foi conduzido com onze participantes, submetidos a uma situação de interação com outros CoDAs e falantes monolíngues. Corroborando os estudos apresentados por Petitto et al. (2001), os resultados do trabalho revelam que $95 \%$ dos participantes produziam code-blending em situações de interação com falantes multimodais, em contraponto a enunciados em uma única língua (inglês ou ASL) quando em meio a interlocutores unimodais.

Como foi indicado anteriormente, um dos trabalhos que mais contribuiu com a presente reflexão é o de Perlin (1998), que, embora disserte também acerca da produção do fenômeno, tem foco na construção das identidades. A autora infere dos resultados obtidos de sua investigação que a forma como o sujeito é interpelado no meio em que vive influenciará a construção de sua identidade, sendo esse o fator predominante na produção de code-blending em discursos produzidos por Surdos bilíngues português e Libras.

Partindo de outra perspectiva, Rodrigues (2013) pesquisou a ocorrência do codeblending por intérpretes de conferência CoDAs e não CoDAs, a partir de estratégias específicas de tradução do português para a Libras, tais como prolongamentos, repetições e pausas, e alguns fenômenos ocorridos durante o processo de Interpretação Simultânea, como code-blendings e code-switchings. Rodrigues sugere que é justamente a diferença de modalidades que possibilita ao ILS despender um esforço menor que o intérp rete de LO, pelo fato de que a memória auditiva dos ILS não sofre interferência da própria voz. Já em uma interpretação de LO, o intérprete tem que lidar com a informação recebida e o monitoramento de sua própria interpretação enquanto fala. Quadros, Lillo-Martin e Emmorey (2016) avigoram essa tese, afirmando que é possível produzir duas línguas simultaneamente sem prejuízo sintático para ambas, já que a produção do code-blending sempre envolve uma proposição e uma derivação sintática, sendo congruentes do ponto de vista sintático e redundantes do ponto de vista semântico.

As pesquisas acima apresentadas sinteticamente e que fundamentam o presente trabalho serão descritas mais detalhadamente abaixo, no intuito de delimitar os diferentes perfis de falantes que produzem o fenômeno em discussão.

\section{Code-blending e perfil de falantes}

Code-blending produzido por Surdos (X Comunicação Total)

Como citado, Perlin (1998) explica que a forma pela qual o sujeito é interpelado no 
meio em que vive influenciará diretamente a construção de sua identidade. A partir de entrevistas com sujeitos Surdos, apresenta diferentes possibilidades para a constituição das identidades de pessoas Surdas, destacando três delas que podem favorecer a ocorrência do code-blending: a de transição, a flutuante e a híbrida. Uma breve análise de como são constituídas as identidades faz entender que alguns fatores extralinguísticos, tais como a imposição da oralização por parte da família na fase de aquisição e o ambiente escolar e social do falante, também favorecem a produção de code-blending por Surdos.

A identidade "de transição" refere-se a Surdos que "transitam" entre o mundo ouvinte e a comunidade Surda. Ressalta-se que cerca de $90 \%$ das crianças Surdas nascem em famílias de pais ouvintes, muitos submetidos a um processo de oralização por pressão da família, "uma realidade particularmente perturbadora" (p. 20). A autora mostra como, a partir da aquisição da Libras (que pode ocorrer tardiamente), o Surdo inicia então um processo oposto de "desouvintização", e passa a se identificar com a língua de sinais, aceitando-se como Surdo. Observa também que, embora não se comuniquem por meio do aparelho fonador enquanto sinalizam, podem produzir algumas palavras ou frases na língua oral, audíveis ou sussurradas, completas ou incompletas, de acordo com o período ao qual foram expostos à oralização.

A segunda categoria, a "identidade flutuante", também caracteriza o sujeito Surdo que "flutua" entre o mundo ouvinte e o Surdo, porém não tendo consciência de sua surdez e não se identificando com a comunidade Surda. O estudo de Perlin (1998, p. 22) revela que a maioria são Surdos profissionalizados que não conseguem interagir com ouvintes por falta de proficiência em língua oral, e, paralelamente, não se sentem pertencer à comunidade Surda por também não alcançar fluência em língua de sinais. As entrevistas conduzidas pela autora revelam que a identidade flutuante favorece a produção de code-blending na medida em que os sujeitos se utilizam de todos os recursos possíveis por possuírem um repertório limitado em ambas as línguas.

O terceiro e último tipo de identidade repertoriado pela autora, com o qual ela própria se identifica, é a "híbrida", em que o sujeito se sente pertencer a ambas as comunidades, ouvinte e Surda. Geralmente nascem ouvintes, com o tempo perdem a audição, aprendem Libras e passam a se comunicar em língua de sinais, ainda que sua conceptualização esteja ancorada na língua oral. A pesquisa revela que esses sujeitos alternam e sobrepõem as línguas para atender à expectativa de cada público. Dominam ambas as normas, do português falado e da Libras, e se adequam a seus interlocutores de acordo com a situação de interação: "quando estou num universo ouvinte, oralizo, quando eu quero me expressar pela minha comunidade eu me expresso pela língua de sinais, as duas línguas me atendem" (PERLIN, 1998, p. 20).

\section{O code-blending produzido por CoDAs}

Souza (2014) explica que há vários perfis de CoDAs, alguns não possuindo proficiência em Língua de sinais e não fazendo parte da comunidade Surda, outros (sendo a maioria) 
"crescem em um ambiente bilíngue e seguem a profissão de ILS" (2014, p. 33). Em sua pesquisa, dos oito CoDAs entrevistados com o objetivo de comparar as experiências e trabalhar a questão da construção de identidade desse grupo, sete afirmaram atuar com interpretação para os pais e para os amigos Surdos, desde bem cedo, o que os fez transitar entre os dois mundos, e aprender desde a "tenra idade as questões que envolvem o ato de interpretar, mesmo que não profissionalmente" (p. 127).

Diversos autores, tais como Sousa e Quadros (2012); Quadros, Lillo-Martin e Pichler (2013); Quadros, Lillo-Martin e Emmorey (2016) e Quadros (2017) também apresentam estudos com CoDAs, ainda que na perspectiva da aquisição linguística desse grupo, investigando questões como línguas de herança, língua materna, transição entre as culturas Surda e ouvinte, a própria sobreposição de línguas, além de abordar questões de identidade. As pesquisas revelam que os filhos de pais Surdos adquirem a Libras como língua primeira, por estarem em contato constante com eles. Vivem, entretanto, também em um mundo de sons, tendo acesso concomitante à língua oral de seu país, produzida quando avós, primos, tios e demais familiares visitam a família, na televisão, ou ainda com os vizinhos. São assim bilíngues bimodais:

Os filhos ouvintes de pais Surdos, os CoDAs, representam um grupo de bilíngues bimodais que têm uma língua de herança em língua de sinais e estão em um país que usa uma língua falada de forma irrestrita em diferentes espaços sociais. Esses sinalizantes de herança representam um grupo de bilíngues que também são bimodais, pois as línguas que adquirem se apresentam em diferentes modalidades (QUADROS, LILLO-MARTIN, EMMOREY, 2016, p. 140).

Partindo do princípio de que as identidades estão em constante construção e mudança por meio de processos de adaptação e negociação, de acordo com as circunstâncias, esses falantes escolhem alternar da Libras para o português, ou vice-versa, sobrepondo as modalidades e produzindo code-blending, sem nem mesmo se darem conta, como explica Quadros (2017, p. 141): "Elas podem usar o modo bimodal ou podem evitá-lo dependendo com quem estejam conversando". Porém, alguns podem ter mais afinidade com o português, pelo fato de serem ouvintes e sofrerem influência da língua falada com mais frequência. Trata-se ainda da língua falada e ensinada na escola, a mais prestigiada, a língua da maioria, a língua que consta nos documentos oficiais:

Também, há uma forte influência da língua falada em suas escolhas, uma vez que essa língua passa a ser primária, apesar de distinguirem entre os contextos falados e em sinais. Quando essas crianças crescem, é possível observar efeitos específicos no desenvolvimento da linguagem (QUADROS, LILLO-MARTIN, EMMOREY, 2016, p.) 141).

Por essa razão, eles são os maiores produtores de code-blending: crescem em um ambiente bilíngue desde o nascimento e grande parte continua convivendo com os Surdos quando adultos, não sendo necessário escolher em que momento usar uma língua ou outra, o que torna a simultaneidade natural.

Streiechen e Krause-Lemke (2013), em um estudo de caso com duas crianças 
ouvintes cuja aquisição linguística se deu com um pai ouvinte e uma mãe Surda, mostram que o fato de a mãe ser Surda não causou nenhum tipo de prejuízo ao desenvolvimento linguístico, cognitivo ou social dos filhos, pois as crianças aprenderam a implementar estratégias de comunicação para interagir com os pais. É na escola que aprenderão que há "diferença" entre as línguas e entre suas gramáticas, podendo preferencialmente se identificar com a Libras ou com o português, de acordo com cada indivíduo. Com efeito, a própria criança ouvinte pode se sentir mais à vontade com a Libras, como mostra o excerto abaixo:

(...) pode se tornar um ouvinte diferente dos outros por apresentar identidade "Surda" e, ainda, diferente dos Surdos por ter experiências auditivas. Muitas crianças ouvintes, quando em contato com a mãe Surda, adquirem fluência na língua de sinais e, em alguns casos, a língua de sinais torna-se a primeira língua ou Língua 1 (L1) dessas crianças (STREIECHEN; KRAUSE-LEMKE, 2013, p. 6).

Andrade (2011), em uma pesquisa de cunho sociológico sobre o processo de construção de identidade do grupo, entrevistou sete CoDAs membros da comunidade Surda, questionando a relação familiar e a percepção do ouvir e não ouvir para esse grupo. Para o autor, a postura adotada pelos participantes da pesquisa traduz uma luta pela expressão de sua identidade, pela valorização da diversidade e pela solidariedade (p. 115), sendo no comportamento que os indivíduos adotam frente à comunidade Surda que eles expressam a diferença: "meus pais são Surdos, não são deficientes auditivos" (p. 115). Outro fator relevante dessa pesquisa é o fato de o autor explicar que, embora não tenha feito as perguntas em Libras, os participantes respondiam ora em Libras, ora em português, produzindo fenômenos de "sobreposição de fala" (p. 71). O autor conclui sua pesquisa explicando que as identidades adquirem o valor de discurso, através da postura adotada por essas pessoas, visto que vivem em mundos diferentes, o ouvinte e o Surdo.

Pereira (2013), em uma pesquisa sobre as relações entre pais e filhos Surdos, pesquisou três famílias de pais Surdos com pelo menos um filho ouvinte. Ele abordou questões como: a descoberta de ser ouvinte, o comportamento de tutor dos pais imposto pela necessidade de interpretação, a responsabilização precoce desses sujeitos, a decisão de escolha profissional na idade adulta etc. A pesquisa, além de entrevistas com as famílias, também apresenta um relato autobiográfico, onde o autor revela que quando os pais se casaram se afastaram da comunidade Surda. Assim, cresceu achando que era o único filho de pais Surdos, só descobrindo a existência de outros iguais a ele na fase adulta, quando foi trabalhar como intérprete (p. 64). O autor explica que, embora o convívio com os pais fosse harmonioso, pertencer a uma sociedade excludente lhe impôs desafios, compartilhados pelos outros participantes da pesquisa. Conclui a pesquisa explicando que crescer em um ambiente bilíngue pode se tornar um problema quando não se trata de línguas de prestígio. $\mathrm{O}$ caso da Libras e do português constitui um desafio devido ao ambiente excludente enfrentado pela pessoa Surda. 
Silva (2016), por sua vez, pesquisou algumas experiências de interpretação na infância dos CoDAs que os levaram a escolher a profissão de Intérprete de Língua de Sinais (ILS). Por meio de um questionário eletrônico, em que coletou informações de dezesseis participantes de um grupo de CoDAs cadastrados em uma rede social, comparando seus relatos de experiência, a autora conclui que o vínculo afetivo e cultural se torna um motivo substancial para a atuação como ILS (p. 188). A pesquisadora, que também se identifica com esse perfil, explica que um outro fator comum aos CoDAs é a busca pela formação profissional, que não raro é incipiente.

O code-blending produzido por CoDAs e ouvintes falantes de Libras como L2 em situação de interpretação

Rodrigues (2013) pesquisou como intérpretes CoDAs e não CoDAs lidam com a diferença de modalidade entre uma língua oral e outra de sinais. Ele apresenta estratégias específicas de tradução do português para a Libras, tais como: prolongamentos, repetições e pausas, e alguns fenômenos ocorridos durante o processo de Interpretação Simultânea, como code-blendings e code-switchings. Sua pesquisa envolveu dez intérpretes, sendo cinco CoDAs e cinco não CoDAs, em um processo de interpretação de um texto do português para a Libras. Entrevistas conduzidas com cada participante a respeito das escolhas lexicais durante a interpretação contribuíram para desvendar o processo cognitivo por meio das suas escolhas tradutórias. Para o autor, "o contexto não é algo fixo e alheio aos interlocutores nem dado a priori, ao contrário, ele seria construído através da manifestação mútua dos ambientes cognitivos dos interlocutores" (RODRIGUES, 2013, p. 59). A comunicação, portanto, segundo ele, fundamenta-se na cognição, e não na linguística. Entretanto, ao discorrer sobre os processos tradutórios dos intérpretes, Rodrigues (2013, p. 44) explica que "[...] há poucas evidências de que o intérprete realize uma atividade diferente daqueles que interpretam entre duas línguas orais; a única diferença, talvez, resida no fato de que transitam entre diferentes modalidades", visto que as LS permitem a alteração de modalidade durante a interpretação. Como visto, é a diferença de modalidades que possibilita ao ILS despender um esforço menor que o intérprete de língua oral (LO), pelo fato de que a memória auditiva dos ILS não sofre interferência da própria voz. Já em uma interpretação de LO, o intérprete tem que lidar com os enunciados que recebe e o monitoramento de sua própria interpretação enquanto fala. Essa diferença também permite que haja uma sobreposição de modalidades, pois os tradutores e intérpretes podem produzir sinais com as mãos e, ao mesmo tempo, palavras de uma língua oral.

O autor, em sua pesquisa, filmou dez traduções a prima vista de um texto do português para a Libras, investigando o processo tradutório por meio das escolhas lexicais dos participantes. Constatou que os participantes produziam code-switching, ou seja, alternância das modalidades, ora produzindo trechos em português, ora voltando a se expressar em Libras. Entretanto, o que mais ocorria era o code-blending, ou sobreposição de línguas (RODRIGUES, 2013, p. 49). Embora a sobreposição não fosse seu objeto de estudo, o 
autor descreveu como ocorreu cada aspecto do fenômeno, documentando o número de ocorrências, e comparando as produções de CoDAs e Não CoDAs (p. 103). Os dados mostram que um discurso sobreposto pode vir tanto de CoDAs como de Não CoDAs.

\section{Análise dos dados}

A análise conduzida, inspirada nos trabalhos e paradigmas metodológicos apresentados anteriormente, focou no perfil sociolinguístico (Surdo oralizado, CoDA, Ouvinte falante de Libras como L2), em características identitárias (fluida ou híbrida) e gêneros discursivos produzidos pelos falantes (narração, justificação, enfatização, argumentação etc.). Buscou-se analisar os dados linguísticos levando em consideração metadados, ou seja, elementos situacionais e discursivos coletados on-line - enquanto pressuposições contextuais sobre os falantes, informações de background -, possibilitando inferências para embasar a interpretação.

Foram analisados vídeos públicos extraídos das plataformas do YouTube e Facebook em que participantes realizam code-blending ${ }^{5}$ em situações reais de produção do fenômeno. A seleção dos vídeos foi pautada por alguns critérios determinados com base nas hipóteses preliminares, segundo as quais os perfis de falantes eram determinantes na produção do fenômeno. Buscou-se retratar/ilustrar a produção do fenômeno de acordo com alguns perfis de falantes: Surdos oralizados, CODAs e ouvintes falantes de Libras como L2.

O pré-requisito central foi de identificar situações espontâneas de produção do codeblending, isto é, uma situação real de comunicação. O corpus foi construído exclusivamente com vídeos disponíveis em plataformas de acesso público e a partir de informações metalinguísticas também tornadas públicas on-line. Assim, os vídeos/falantes correspondentes a cada perfil foram selecionados de acordo com alguns critérios que pareciam, a partir das observações preliminares, incidir na produção do fenômeno: falantes com fluência em Libras de modo a possuir um certo "capital linguístico" (BOURDIEU, 1996) reconhecido pela Comunidade Surda. No caso dos Surdos oralizados, a escolha recaiu igualmente sobre falantes que se encaixavam na categoria sugerida por Perlin (1998) de "identidades híbridas", sendo o perfil que tende a favorecer mais sistematicamente a produção do fenômeno, já que transitam continuamente entre as comunidades Surda e ouvinte e têm proficiência nas duas línguas.

Com o uso do Elan (ilustração abaixo), foi possível comparar a produção simultânea por um mesmo falante nas duas línguas, buscando focar na relação que se estabelece entre os enunciados sobrepostos, em termos de influência recíproca.

\footnotetext{
${ }^{5}$ As transcrições dos vídeos foram realizadas com o sistema ELAN, elaborado pelo Instituto de Psicolinguística Max Planck, Nijmegen, nos Países Baixos (referência). De acordo com Pêgo (2013, p. 61), trata-se hoje da ferramenta mais adequada para a pesquisa da língua de sinais, pois facilita as anotações de fala e/ou sinais associados e as trilhas de transcrição. Para maiores informações acerca do ELAN, acessar o site: https://tla.mpi.nl/tools/tla-tools/elan/elan-description/.
} 
Para cada vídeo analisado, são destacados a situação de interação e o gênero discursivo que os caracterizam, assim como metadados a respeito do falante obtidos por meio de pesquisas bibliográficas on-line (CV Lattes, dados bibliográficos e publicações produzidas pelos falantes, relatos de experiência disponíveis on-line).

Figura 1 - Exemplo de interação (vídeo 1)

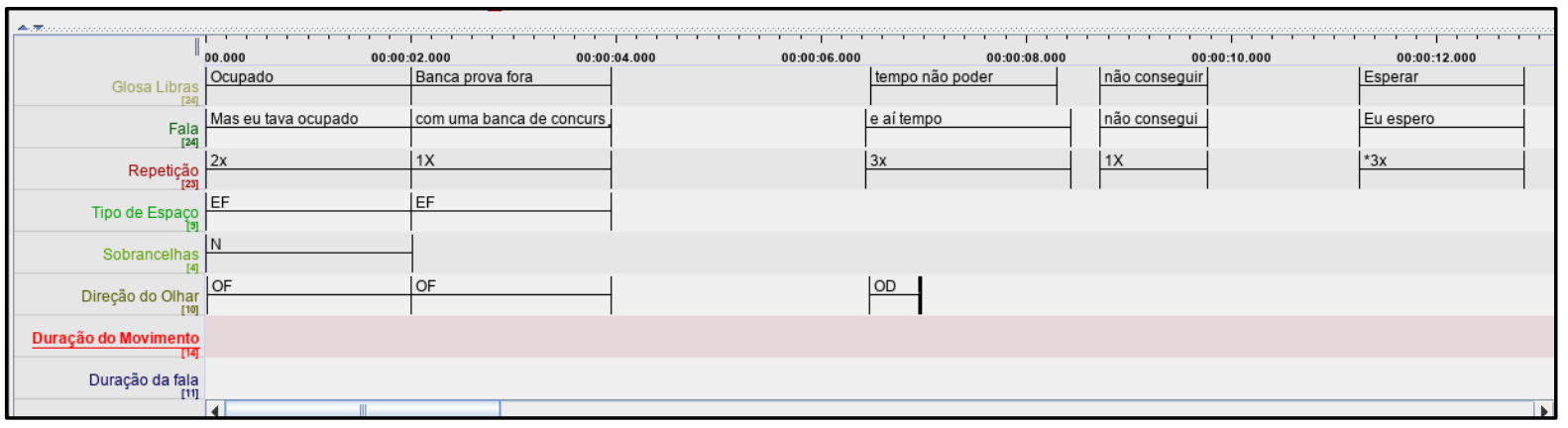

Fonte: as autoras.

Produção de code-blending por um intérprete - Vídeo 1 (parte 1)

Quadro 1 - Perfil sociolinguístico do falante 1

Situação de interação: interpretação simultânea de
palestra
Gênero discursivo: interpretação/paráfrase/imitação
Metadados: O participante trabalha há mais de 15 anos
com tradução e interpretação de Libras, atua com
Tradução e Letramento para o Surdo no Ensino Superior e
é reconhecido pela Comunidade Surda, por sua atuação
com teatro e gêneros textuais artísticos e literários, além
de compor a Gestão atual da Federação Brasileira das
Associações dos Profissionais Tradutores e Intérpretes e
Guia-Intérpretes de Língua de Sinais - FEBRAPILS.
Sugere-se que o falante ouvinte em questão também se
enquadra na identidade hibrida descrita por Perlin para
caracterizar falantes Surdos, por pertencer a ambas as
comunidades, Surda e ouvinte.

O primeiro vídeo analisado refere-se à 6ạ audiência do processo de instituição do Projeto de Lei da Câmara 103/2012 que aprova o Plano Nacional de Educação ${ }^{6}$. Em seus primeiros minutos (até $3 \mathrm{~min} 32 \mathrm{~s}$ ), foram analisados trechos de interpretação simultânea de português para Libras em que o intérprete produz um tipo de code-blending particular, com a ocorrência pontual de palavras em português sussurradas ${ }^{7}$.

\footnotetext{
${ }^{6}$ Esse vídeo é de acesso público e está disponível no site: https://www.youtube.com/watch?v=ds4MsrLKM1w. Acesso em: 23 de abr. de 2020.

${ }^{7}$ A Glosa foi transcrita em letras maiúsculas, seguida dos enunciados em português, transcritos em letras minúsculas, com exceção da primeira letra da frase.
} 
(1)

1) DESCULPA, OUTROS PAÍSES COPIAR

Outros cota

2) PAÍSES ENTÃO TER MARAVILHOS@

Países tem ex. maravi.

3) AQUI BRASIL VEJA EXEMPLO SINAL FLORIANÓPOLIS,

Olha exemplo Flo.

4) AH FLORIANÓPOLIS OUTRO REALIDADE

Ah Flo. Ou é

5) É ÚNICO

É um

6) [SERÁ?]

7) NÃO AMPLITUDE R-E-D-E-X TER DIREITO ENSINAR TUDO

Rede tem direito tu.

8) SE ESSE CÂMARA É COMO ACEITAR OU NÃO

Se esse

9) TER ATÉ DIRETO COLOCAR INTÉRPRETE CÂMARA

Aceitar essa

10) TAMBÉM ACEITAR BARREIRA PESSOA ENTRAR

Também

11) DEFICIENTE NÃO TER ACESSIBILIDADE.

Não tem

Infere-se que o intérprete produz enunciados em Libras sem interferência do português, que ocorre apenas por meio da produção fragmentada de palavras sussurradas (maravi., e Flo, se, esse, também). Esse exemplo convalida as pesquisas de Rodrigues (2016), que sugere que esse tipo de code-blending, tipicamente produzido em contexto de interpretação para a Libras, intervém enquanto estratégia de realce/acompanhamento da sinalização, lembrando que, de acordo com Rodrigues, a interpretação é uma situação que favorece a produção do fenômeno.

Produção de code-blending por Surda oralizada - Vídeo 1 (parte 2)

Quadro 2 - Perfil sociolinguístico do falante 2

Situação de interação: palestra
Gênero discursivo: argumentação
Metadados: A participante cresceu no Estado de
Minas, onde frequentou o Centro Verbo Tonal -
Clínica Oralista de Belo Horizonte - dos 2 aos 12 anos
de idade. Concomitantemente, tinha contato
constante com seus pares Surdos. Em sua Tese
IMPLANTE COCLEAR NA CONSTITUIÇÃO DOS SUJEITOS
SURDOS, a autora explica que era obrigada a oralizar,
fazer leitura labial e proibida de sinalizar. Explica ainda
que se sentia livre ao sinalizar escondido com os
colegas Surdos com os quais convivia. O que configura
sua classificação nas identidades híbridas já
apresentadas. Atualmente, ela milita em prol dos
interesses da Comunidade Surda em projetos escritos
para o Congresso Nacional e políticas públicas de
acesso aos Surdos.


No segundo trecho do mesmo vídeo, foram analisados enunciados (de 3:54 até 4:25) nos quais a participante Surda argumenta acerca da importância da educação bilíngue para Surdos. Neles, o fenômeno de code-blending comparece como processo típico de Surdos oralizados.

(2)

1) EU, HORA MEU, ESPERAR

O momento é meu

2) EU JÁ RESPEITAR HORA SUA

Eu já respeitei o momento

3) VOCÊ RESPEITAR HORA MEU

Respeita meu momento

4) POR FAVOR

Ok.

5) ORGANIZAR, ESSA, PESSOA, EXEMPLO DENTRO

Calma, porque ela é única exemplo

6) G-A-S-T-O-S D-A PÚBLICA NÃO ABANDONAR SURDO?

Escola pública não, surdo

7) EU FENEIS B-D-S QUÊ NÃO REPRESENTA SURDO?

Feneis não representa o surdo?

Percebe-se que a maioria dos enunciados são produzidos de acordo com as normas de ambas as línguas, instaurada uma fronteira clara entre a Libras e o português. Vale, entretanto, ressaltar algumas divergências semânticas: em 4), o sinal produzido em Libras de POR FAVOR sobrepõe-se ao o português Ok. Do mesmo modo, em 5), à palavra calma, em Libras, corresponde o sinal de organizar. Já em 6), digita (Gastos) e enuncia escola em português, ideias que comparecem de forma complementar (gastos da escola pública). Infere-se que ocorre uma interlocução entre os dois enunciados produzidos simultaneamente, um complementando o outro, em ambas as línguas.

Produção de code-blending por Surda oralizada - Vídeo 2

Quadro 3 - Perfil sociolinguístico do falante 3

Situação de interação: entrevista
Gênero discursivo: narração (conta como foi ser a
primeira doutora surda no Brasil)
Metadados: A participante ficou surda na infância
como consequência de uma meningite; na
adolescência, conviveu mais com pessoas ouvintes do
que com surdas; ao final da adolescência, passa a ter
contato com a comunidade surda. Em sua dissertação
Histórias de vida surda: Identidades em questão, ela se
identifica como pertencente à identidade híbrida.
Atualmente é professora da Universidade Federal de
Santa Catarina - UFSC, atuando com os temas de
Surdez e diferença, Cultura, Educação e Identidade.


Nesse vídeo, foram analisados alguns enunciados de uma entrevista concedida à TV INES $^{8}$ (de 1:14 até 2:00), acerca da experiência pessoal da pesquisadora, do seu trabalho e da sua contribuição com as conquistas da Comunidade Surda. O vídeo encena falas exclusivamente em Libras, com tradução off para o português e uso de legendas, não sendo possível ouvir os enunciados em português do code-blending produzido, mas apenas acompanhá-los por leitura labial. Antes de iniciar a conversa, a entrevistadora apresenta uma biografia da entrevistada Surda. A primeira pergunta questiona como é ser a primeira Surda Doutora do Brasil. Segue a resposta transcrita:

(3)

1) PRAZER TAMBÉM, VOCÊ PASSADO EU JUNTO, BOM. PRAZER.

Oh Clarissa, Prazer, junto ótimo.

2) ENTÃO QUE É PESADO PORQUE PRIMEIRA, LUTAR, CHAMAR, EU CHAMAR

Nossa é sim, um pouco pesado porque a primeira precisa falar eu chamar

3) (REUNIR^TRAZER) A MIM. COMO FAZER?

oh vamos fazer, não temos nada

4) NÃO TER NADA PASSADO, É CONSEGUIR HOJE ESCRITA NÃO TER, COMO FAZER?

Agora tem, escrita não tinha, como fazer?

5) PRECISA BUSCAR, BUSCAR, BUSCAR, SURDOS TODOS, PRECISA QUÊ? FAZER, PRECISA SENTAR.

Todos nós fazer, precisa ficar sentada, sala junto,

6) IMAGINAR JUNTOS FAZER PRIMEIRA CONFERÊNCIA DIREITOS PESSOA SURDA.

Fazer a primeira conferência direitos da pessoa su[...]

Embora as duas línguas sejam produzidas simultaneamente, identifica-se a predominância da Libras nas sentenças 4), 5) e 6) em que sinais são produzidos sem a enunciação simultânea de palavras em português, respeitando a particularidade da Libras de produzir indagações ao término das frases (a exemplo de 3) e 4): como fazer? precisa quê? como fazer?), além de recorrer a um classificador na sentença 3) (REUNIR^TRAZER) que não comparecem no português. Na sentença 6), observa-se a supressão da palavra Surda, que aparece apenas pela metade. Como a interlocutora é proficiente em Libras, não há necessidade das verbalizações, que ocorrem apenas enquanto mistura de línguas.

Produção de code-blending por Surda oralizada - Vídeo 3

Quadro 4 - Perfil sociolinguístico do falante 4

Situação de interação: Entrevista
Gênero discursivo: Argumentação
Metadados: A participante nasceu ouvinte, mas, ao
quatro dia de vida, pegou um forte resfriado e precisou
fazer uso de antibióticos, o que acarretou o
enfraquecimento dos nervos auditivos, gerando uma
surdez profunda. A escola para Surdos onde estudava
proibia a prática da língua de sinais, impondo a
metodologia oralista.

${ }^{8}$ Esse vídeo é de acesso público e está disponível no site: https://www.youtube.com/watch?v=uOfvtnGA9 g. Acesso em: 12 de março de 2020. 
Quadro 4 (continuação) - Perfil sociolinguístico do falante 4

A aprendizagem de Libras só ocorreu aos 15 anos. Em
um de seus livros, A imagem do outro sobre a Cultura
Surda (2009), ela narra que o oralismo foi imposto
pelos ouvintes como forma de normatização das
práticas linguísticas do Surdo, imposição que ela
vivenciou ao longo da vida, enquadrando-se assim na
descrição de Perlin de "identidade híbrida".
Atualmente, participa da gestão do ensino especial no
MEC em defesa dos interesses da Comunidade Surda.

O vídeo analisado apresenta uma entrevista concedida à emissora RTV Caatinga, da Universidade Federal do Vale do São Francisco - UNISVAF ${ }^{9}$. Foram analisados os enunciados de (3:40 até 4:20). Assim como no vídeo 2 , há uma tradução off para o português da fala da participante, o code-blending também podendo ser acompanhado apenas pela leitura labial. O vídeo não faz uso de legendas; além disso, como a entrevistadora não sabe Libras, há uma intérprete que produz a mediação do diálogo. Esta análise recai sobre a resposta a uma das perguntas feitas pela entrevistadora, cujo foco era o ponto de vista da pesquisadora sobre da Educação de Surdos no Brasil. Ela indaga especificamente se o ensino de Libras deveria ser obrigatório para Surdos e ouvintes no Brasil, ao que a pesquisadora produz a seguinte resposta:

(4)

1) EU PENSAR IMPORTANTE TODOS OUVINTES APRENDER LIBRAS

Eu acho impo[..] ouvinte aprender Libras

2) PORQUE ACABAR PRECONCEITO TODO, PORQUE MUITO SOCIEDADE VER LIBRAS PARECER MÍMICA, porque acaba com o preconceito [...] muita gente [...] vê os sinais parece é mímica,

3) PARECER NÃO É LÍNGUA, VER LÍNGUA INFERIOR.

Parece que não é língua, parece vê como uma língua inferior,

4) POR ISSO IMPORTANTE DIVULGAR ESSA OBRIGATORIEDADE, por isso é importante [...] seja obrigatória,

5) OUVINTE APRENDER PRINCIPALMENTE QUEM ATUA NO ENSINO os ouvintes aprender, principalmente na área do ensino

6) POR ISSO LIBRAS SURDO TAMBÉM INTERAÇÃO TAMBÉM DIVULGAÇÃO LIBRAS

Por causa que a Libras [...] ao Surdo e também - divulgação da Língua de Sinais tem

Embora a produção em Libras não sofra interferência, observa-se o modo explícito como a participante oraliza, principalmente na sentença 5), com o uso da conjunção (do), característica do português. Algumas palavras pronunciadas de maneira ilegível foram grafadas com [...]. Ressalta-se que não se observa a prevalência de uma língua sobre a outras: os enunciados são produzidos conforme as normas de ambas as línguas, o que revela uma forte capacidade de monitoramento simultânea das línguas sobrepostas.

\footnotetext{
${ }^{9} \mathrm{O}$ vídeo é de acesso ao público e está disponível no site: https://www.youtube.com/watch?v=iREMMncTJaw\&list=WL\&index=21\&t=252s. Acesso em: 20 de março de 2020.
} 


\section{Produção de code-blending por uma CODA - Vídeo 4}

Quadro 5 - Perfil sociolinguístico do falante 5

Situação de interação: interpretação

Gênero discursivo: interpretação

Metadados: A participante desse vídeo é ouvinte, filha de mãe e pai Surdos, militantes da Comunidade Surda, atua há cerca de 30 anos com ensino e interpretação de Libras, também é co-fundadora de um Centro de Cursos de Libras na cidade de Goiânia, instituição à qual pertenceu como professora por cerca de 10 anos. Hoje, é tradutora e intérprete da Universidade Federal de Manaus (UFAM). Embora a categorização sugerida por Perlin foque exclusivamente os Surdos, sugere-se aqui, convalidando a afirmação de Quadros (2017), que, à maioria dos CoDAs, também possa ser atribuída a "identidade híbrida", por ele qualificada para se referir a falantes que transitam entre os mundos Surdo e ouvinte.

O vídeo apresenta conteúdo mensalmente postado para a Comunidade Surda, que traz informações sobre cultura, eventos, acontecimentos e notícias, entre outros ${ }^{10}$. A análise se concentra nos seus minutos iniciais (0:00 até 0:30), em que a falante interpreta para a Libras a notícia enunciada em português, aparecendo em uma janela de Libras no canto superior esquerdo da tela. O som emitido não é o da interpretação, mas o da notícia apresentada pelo repórter. A produção de code-blending também é acompanhada por leitura labial.

1) ENTÃO, AGORA TEM NOTíCIA. PASSADO D-I-T-A-D-O, FALA PRECISA, Ditado

2) ENTRAR PAÍS CONHECER PROFUNDO? NÃO.

Países conhecer profundo

3) VOCÊ VONTADE DE CONHECER COMO? PROFUNDO DIFERENÇAS CULTURAIS PAÍSES

Conhecer como?

4) NÃO-PODER ENTRAR? POSSÍVEL O QUÊ? ÁREA GASTRONOMIA DIFERENTES RESTAURANTES Área

5) ENTÃO, VOCÊ POSSÍVEL, SENTIR EXPERIÊNCIA COMO?

você

6) ADIQUIRIR CULTURA, ENTÃO, AQUI CIDADE GOIÂNIA, TEM POSSÍVEL

Aqui cidade de Goiânia

Observa-se que a Libras predomina na produção, compreendendo-se que os enunciados produzidos em Libras ocorrem sem interferência do português, de modo fragmentado, com enunciação de algumas palavras esporadicamente sussurradas (ditado,

\footnotetext{
${ }^{10} \mathrm{O}$ vídeo é de acesso ao público e está disponível no site: https://www.youtube.com/watch?v=SNAWR42irE4. Acesso em: 04 de junho de 2020.
} 
conhecer como, área). Vale observar que as palavras são enunciadas em português simultaneamente especialmente quando essa palavra é digitada em Libras (a exemplo de DI-T-A-D-O). Esse exemplo convalida as pesquisas de Rodrigues (2016), que sugerem que esse tipo de code-blending, tipicamente produzido em contexto de interpretação para a Libras, intervém enquanto estratégia de realce/acompanhamento da sinalização e também corrobora com os as pesquisas de Quadros (2012, 2013, 2016 e 2017) acerca da produção linguística dos CoDAs.

Produção de code-blending por ouvinte, Libras como L2 - Vídeo 5

Quadro 6 - Perfil sociolinguístico do falante 6

\begin{tabular}{l} 
Situação de interação: monólogo/nota de apelo ao \\
público \\
Gênero discursivo: argumentação política \\
Metadados: A participante do vídeo adquiriu Libras \\
como L2 e atua há mais de 20 anos no Ensino Especial, \\
em Canoas, cidade do interior do Rio Grande do Sul. \\
Como é participante da Comunidade Surda e ocupa \\
cargo político, gravou um vídeo apressadamente, sem \\
legenda e sem intérprete, a ser colocado no ar logo na \\
manhã seguinte à prova do MEC. Sugere-se, nesse \\
exemplo, enquanto hipótese a ser validada, que o \\
code-blending seria produzido como estratégia \\
discursiva para atingir dois públicos simultaneamente \\
(Surdos e ouvintes). \\
Sugere-se que o falante ouvinte em questão também \\
se enquadra na identidade hibrida descrita por Perlin \\
(1998) para caracterizar falantes Surdos, por \\
pertencer a ambas as comunidades, Surda e ouvinte. \\
\hline
\end{tabular}

O vídeo 5, gravado em 13 de novembro de 2017, foi divulgado para a comunidade Surda em resposta às críticas ao $\mathrm{MEC}$ com relação à prova do Enem realizada na véspera, em 12 de novembro. No vídeo, a professora encontra-se em uma sala de escritório sentada em uma cadeira, com as mãos sobre a mesa com bandeiras ao fundo. $O$ vídeo tem a duração de 4:29; a análise refere-se a 1:00 de vídeo. ${ }^{11}$

(6)

1) OI TUDO BEM, PESSOA

Oi tudo bom, pessoal

2) HOJE RESOLVER, FAZER AGORA

Ah... hoje eu resolvi fazer né...

3) MOSTRAR, DIVULGAR, MINHA OPINIÃO

Mostrar ou divulgar minha opinião

4) ONTEM TEMA, MUITO MUITO DISCUSSÃO PESSOAS

\footnotetext{
${ }^{11} \mathrm{O}$ vídeo é de acesso público e está disponível em: https://www.facebook.com/mari.mantelli.3/videos/vb.100001828267298/1679896532081273/?type=2\&video source=user video tab. Acesso em: 07 de setembro de 2019.
} 
Sobre ontem, o assunto é muito muito muito muito, ontem tem debatido, discutido com as pessoas

5) TEMA E-N

Sobre o assunto do, da Prova

6) PROVA E-N-E-M

Prova do Enem

7) -

Que é a...

8) DESAFIO ENSINAR SURDO BRASIL

Os desafios para formação educacional do Surdo no Brasil

A sentença 1) inicia-se com uma saudação (oi tudo bem) nas duas línguas, atendendo a ambos os públicos. Nas sentenças 2) e 3), a professora, reafirmando sua intenção de emitir sua opinião em Libras, produz sinais (RESOLVER, FAZER, MOSTRAR, DIVULGAR) de acordo com o padrão gramatical da Libras. Em português, na segunda sentença, o enunciado constrói-se em ritmo mais lento, de modo a acompanhar os sinais produzidos, embora também de acordo com as normas do português. Em 4), observa-se ocorrência de mistura de línguas, com predominância da Libras. Ao duplicar o sinal (MUITO), enuncia paralelamente em português quatro vezes a palavra (muito), seguidas por um decalque sintático (ontem tem debatido). Em 5), ao esclarecer o tema do vídeo, produz o sinal (TEMA) simultaneamente à palavra enunciada em português (assunto), voltando assim a produzir uma fronteira entre as sentenças de acordo com as normas de ambas as línguas. Em 6), enuncia-se o assunto-chave do vídeo - a prova do Enem - sobrepondo soletração e fala. Em 7), a falante consulta seu celular sobre o tema da prova, não podendo sinalizar simultaneamente. Em 8), explica o tema da redação simultaneamente em português e Libras (desafios para a formação educacional do Surdo no Brasil), substituindo o termo (formação educacional) pelo verbo (ENSINAR) em Libras.

Produção de code-blending por ouvinte, Libras como L2 - Vídeo 6

Quadro 7 - Perfil sociolinguístico do falante 7

Situação de interação: monólogo/nota de apelo ao público (pedido de voto)

Gênero discursivo: propaganda política

Metadados: A participante, que adquiriu Libras como L2, atua como tradutora e intérprete há mais de 20 anos, participando das gestões de escolas inclusivas, da criação de cursos de Libras para a Secretaria de Educação. Hoje, é professora da área de Estudos da Tradução da Universidade de Brasília.

Sugere-se que o falante ouvinte em questão também se enquadra na identidade hibrida descrita por Perlin para caracterizar falantes Surdos, por pertencer a ambas as comunidades, Surda e ouvinte.

O vídeo, que apresenta uma mensagem de feliz ano novo à Comunidade Surda, foi analisado em seus primeiros 0:38. A protagonista do vídeo, ao desejar um feliz ano novo ao 
seu público, aproveita para pedir votos para uma competição, concorrendo a uma filmadora. Não há legendas, nem intérpretes, mas é possível ouvir os enunciados em português e acompanhar a sinalização em Libras.

(7)

1) INTÉRPRETAÇÃO LIBRAS [...]

[...]um bom trabalho de intérprete de Língua de Sinais

2) [...] APROVEITAR MEU GOSTAR DEUS

e agora graças a Deus já

3) SURDO ACESSIBILIDADE, COMUNIDADE SURDA ACESSO

tem acessibilidade em muitos espaços e o surdo vai ter mais acesso.

4) ESSE O QUÊ? [...]

Bom, o bolo representa o que?

5) ACONTECER QUÊ? CASAMENTO, OUTUBRO 2010.

O casamento que vai acontecer dia 23 outubro de 2010.

6) FILMAR PRECISA EU QUERER MUITO GANHAR FILMADORA

e eu quero muito ganhar essa máquina pra poder filmar minha lua de mel.

7) SEMANA PRÓXIMA EU ESPERANÇA, MARIDO SURDO TUDO LIBRAS

Meu marido é surdo, e tudo que a gente faz é por língua de sinais,

8) ME AJUDAR. VOTAR EU.

então eu to esperando realmente ganhar, me ajuda, vota em mim.

Observa-se que há predomínio do português nas sentenças 4) e 8), alguns sinais correspondentes não tendo sido produzidos em Libras, embora seja possível acompanhar os dois discursos simultaneamente. Como se trata de uma fala explicitamente propagandística para ganhar o prêmio, sugere-se aqui também que o code-blending intervém enquanto recurso para ampliar o público-alvo.

À luz das análises dos dados, observam-se características distintas do fenômeno de code-blending de acordo com o perfil do falante e da especificidade da situação, que acarreta gêneros discursivos determinados. No que se refere aos perfis, observam-se Surdos oralizados bilíngues que adquiriram Libras como L2 tardiamente (na adolescência) e outros que foram alfabetizados em português e Libras simultaneamente na prima idade; ouvintes que adquiriram Libras como L2; e CoDA, falante ouvinte que, tal como os dois falantes Surdos, adquiriu ambas as línguas, como línguas primeiras.

Em termos de situação de interação, distinguem-se a interpretação simultânea; a entrevista; o monólogo político; e a palestra. Os gêneros discursivos que caracterizam as produções se desdobram em: interpretação; narração e argumentação política.

Nas situações de interpretação simultânea (vídeo 1), o intérprete produz seus enunciados em Libras padrão ao longo de toda a interpretação, não ocorrendo interferências explícitas de uma língua sobre a outra. Nota-se que não se trata de uma interpretação simultânea de facto, mas da inserção de uma janela de interpretação posterior à ocorrência da audiência. O intérprete, portanto, teve acesso à fala do palestrante em português para elaborar sua tradução. O fenômeno de code-blending ocorre por interstícios 
enquanto acompanhamento da fala, por meio de palavras sussurradas, muitas vezes parcialmente.

Já na produção das participantes Surdas, a todo sinal elaborado corresponde $/ \mathrm{m}$ palavra/s pronunciada/s, com a particularidade de que os enunciados produzidos nas duas línguas simultaneamente se complementam. Sugere-se, enquanto hipótese preliminar, que essa característica resulta do processo de oralização (muitas vezes imposto) de alguns Surdos (identidade híbrida ou de transição), que leva o falante a produzir palavras oralmente, ainda que a língua de conforto seja a Libras.

No caso dos falantes de português como língua primeira e Libras como segunda, observa-se a predominância do português em grande parte das produções, embora seja possível distinguir os enunciados em ambas as línguas.

No caso do CoDA, observa-se que a Libras predomina durante toda sua produção, com palavras enunciadas em português, de modo fragmentado, especialmente quando são digitadas em Libras. Sugere-se, à luz das análises de Rodrigues (2016), que esse tipo de codeblending, tipicamente produzido em contexto de interpretação para a Libras, intervém enquanto estratégia de realce/acompanhamento da sinalização.

Depreende-se dessas observações iniciais que o code-blending ocorre de formas distintas a depender do perfil do falante, embora todos os sujeitos aqui observados possam ser caracterizados como apresentando uma identidade híbrida, e da situação de interação que induz determinados gêneros discursivos.

\section{Considerações finais}

Embasado em pesquisas anteriores sobre o code-blending e sustentado conceitualmente por pressupostos basilares da sociolinguística, o trabalho aqui exposto buscou determinar fatores que circunscrevem a ocorrência desse fenômeno nas situações observadas nessa pesquisa.

Ao final da análise, embora seja possível afirmar que, de forma geral, o fenômeno de code-blending constitui um recurso linguístico alimentado por uma somatória de estratégias discursivas a partir de duas línguas de modalidades diferentes, os dados revelam de forma preliminar que os fatores que favorecem sua ocorrência são distintos de acordo com o perfil dos sujeitos que o produzem e a tipologia das situações de interação e dos gêneros discursivos que dela emergem.

Para além das conclusões que emergem da análise ora apresentada, sugerem-se alguns elementos a serem aprofundados com vistas a generalizações capazes de convalidar estudos anteriores e sistematizar a análise dos fenômenos de contatos de línguas, especialmente o code-blending. Assim, apontamos as seguintes hipóteses a serem comprovadas em futuras pesquisas.

Para os CoDAs, geralmente imersos em duas comunidades linguísticas, o codeblending é produzido com predominância da Libras, enquanto estilo de fala. Por evoluir em ambiente de sobreposição de línguas, em que a língua de sinais é a língua da família e a 
língua oral, a do país onde vivem (dos parentes próximos, dos vizinhos, da escola, do trabalho etc.), compreende-se que esse grupo desenvolva o hábito discursivo da simultaneidade.

Para os ouvintes cuja Libras comparece como L2, a necessidade de atender dois públicos, duas comunidades linguísticas distintas simultaneamente, seja pela falta de um intérprete, ou por acomodação linguística, para se adaptar a seus interlocutores, poderiam ser apontados como fatores de impulsão do fenômeno. Vale sugerir também enquanto hipótese que, ao contrário da situação daqueles que já possuem fluência em Libras, em contexto inicial de aprendizagem, o code-blending poderia ocorrer pela restrição de repertório do aprendiz que busca suprir suas carências no novo idioma recorrendo a sua L1.

Para os Surdos oralizados cujas duas línguas são primeiras (tendo sido adquiridas simultaneamente na prima infância), a produção do fenômeno poderia ser atribuída a características inerentes a seu processo de aquisição, em que ambas as línguas se misturam constantemente em seus enunciados, enquanto estilo de fala. Poder-se-ia sugerir igualmente que o fenômeno seria motivado por questões de identidade, por terem sido obrigados a oralizar, alguns resquícios de fala permanecendo em sua produção discursiva.

Além disso, ainda que o foco da pesquisa não tenha recaído exclusivamente sobre a produção do fenômeno de code-blending por intérpretes, acredita-se que boa parte das estratégias que permeiam essa produção remetem a técnicas de tradução, produzidas em interpretação simultânea, tais como transferência, modulação, explicitação, omissão e decalques sintáticos. Futuras pesquisas ganhariam, portanto, em analisar o code-blending a partir da perspectiva dos estudos da tradução e da compreensão de que a ocorrência do fenômeno compareceria enquanto recurso tradutório. Estudos futuros também poderiam aprofundar as hipóteses aqui apresentadas, buscando determinar que temáticas e organizações interacionais favorecem preferencialmente a produção desse fenômeno por Surdos e ouvintes.

Embora centrada em um fenômeno específico e restrito, a pesquisa insere-se numa perspectiva mais ampla de valorização do multilinguismo e dos direitos linguísticos de minorias. Com efeito, estima-se que mais da metade da população mundial fala pelo menos duas línguas e que $40 \%$ dessa população mistura as línguas em suas práticas diariamente (CORTELAZZO, 2017, p. 1), em diversas modalidades e com características distintas, enquanto recursos linguísticos ou estilísticos, de acordo com as necessidades da interação.

\section{Referências}

ANDRADE, P. R. Identidades dos filhos ouvintes quando os pais são Surdos: uma abordagem sociológica sobre o processo de socialização. 2011. 129 f. Dissertação de Mestrado. Programa de Pós-Graduação em Sociologia, Universidade Federal de Goiás, Goiânia, 2011.

BORTONI-RICARDO, S. M. Manual de sociolinguística. 1. ed., 1a reimpressão. - São Paulo: Contexto, 2017.

BOURDIEU, P. A economia das trocas lingüísticas. São Paulo: Edusp, 1996. 
BRITO, L. F. Por uma gramática de língua de sinais. Rio de Janeiro: Tempo Brasileiro, 1995.

CORTELAZZO, F. Représentation et contrôle des langues chez les bilingues précoces et tardifs: études comportementale, morphométrique et en imagerie fonctionnelle. 2017. Tese de doutorado. Université Toulouse-Jean Jaurès, 2017.

EMMOREY, K.; BORINSTEIN, H.; THOMPSON, R. Bimodal bilingualism: code-blending between spoken English and American Sign Language. 4TH INTERNATIONAL SYMPOSIUM ON BILINGUALISM, 2008. https://doi.org/10.1017/S1366728907003203

GILES, H.; TAYLOR, D.; BOURHIS, R. Toward a theory of interpersonal accommodation through speech: some Canadian data. Language in Society, v. 2. Cambridge: Cambridge University Press, p. 177-192, 1973. https://doi.org/10.1017/S0047404500000701

GOLDFELD, M. A criança surda: Linguagem e cognição numa perspectiva sociointeracionista. 7. ed. São Paulo: Plexus Editora, 1997/2002.

LEITE, C. M. B. Atitudes linguísticas e teoria da acomodação: inter-relação entre Sociolinguística e Psicologia Social. Estudos Linguísticos, São Paulo, v. 40, n. 2, p. 1017-1028, 2011.

NASCIMENTO, L. C. R. Um pouco mais da história da educação dos surdos, segundo Ferdinand Berthier. Grupos de Estudo e Subjetividade, Campinas: Unicamp. E.T.D., v. 7, n. 2, p. 88-97, 2006. https://doi.org/10.20396/etd.v7i2.807

PÊGO, C. F. Sinais não manuais gramaticais da LSB nos traços morfológicos e lexicais: um estudo do morfema-boca. 2013. 87 f. Dissertação de Mestrado. Programa de Pós-Graduação em Linguística, Universidade de Brasília, Brasília, 2013.

PEREIRA, O. R. Nascidos no silêncio: as relações entre filhos ouvintes e pais Surdos na educação. 2013. 140 f. Dissertação de Mestrado. Programa de Pós-Graduação em Educação, Universidade Metodista de São Paulo, São Bernardo do Campo, 2013.

PERLIN, G. T. T. Histórias de vida surda: Identidades em questão. 1998. Dissertação de Mestrado em Educação. Programa de Pós-Graduação em Educação, Universidade Federal do rio Grande do Sul, Porto Alegre, 1998.

PETITTO, L.; KATERELOS, M.; LEVI, B.; GAUNA, K.; TETRAULT, K.; FERRARO, V. Bilingual signed and spoken language acquisition from birth: Implications for the mechanisms underlying early bilingual language acquisition. Journal of child language, Cambridge University, v. 28, n. 2, 453-496, 2001. https://doi.org/10.1017/S0305000901004718

QUADROS, R. M.; LILLO-MARTIN, D.; PICHLER, D. C. O que bilíngues bimodais têm a nos dizer sobre desenvolvimento bilíngue? Letras de hoje, Porto Alegre, v. 48, n. 3, p. 380-388, 2013.

QUADROS, R. M.; LILLO-MARTIN, D.; EMMOREY, K. As línguas de bilíngues bimodais. Revista de Estudos Linguísticos da Universidade do Porto, Porto, v. 11, p. 139-160, 2016.

QUADROS, R. M. de. Língua de Herança: Língua Brasileira de Sinais. Porto Alegre. Editora: Penso, 2017.

RODRIGUES, C. H. A interpretação para a língua de sinais brasileira: efeitos de modalidade e processos inferenciais. 2013. 243 f. Tese de Doutorado. Faculdade de Letras, Programa de Pós-Graduação em Estudos Linguísticos, Universidade Federal de Minas Gerais, Belo Horizonte, 2013. 
SANTIAGO, V. D. A. A. Português e Libras em diálogo: os procedimentos de tradução e o campo do sentido. In: ALBRES, N, de A.; SANTIAGO, V. D. A. A. (Orgs). Libras em estudo: tradução/interpretação. São Paulo: FENEIS, 2012. p. 35-56.

SILVA, M. M. da. Codas Tradutores e Intérpretes de Língua de Sinais Brasileira: percurso para o profissionalismo. 2016. 204 f. Dissertação de Mestrado. Programa de Pós-Graduação em Estudos da Tradução, Universidade de Santa Catarina, Florianópolis, 2016.

SOUSA, A. N. de; QUADROS, R. M. de. Uma análise do fenômeno "Alternância de línguas" na fala de bilíngues intermodais (Libras e Português). ReVEL, v. 10, n. 19, p. 327-346, 2012.

SOUZA, J. C. F. Intérpretes Codas: Construção de Identidades. 2014. 148 f. Dissertação de Mestrado. Programa de Pós-Graduação em Estudos da Tradução. Universidade de Santa Catarina, Florianópolis, 2014.

STOKOE, W. Sign and Culture: A Reader for Students of American Sign Language. Listok Press, Silver Spring, MD, 1960.

STREIECHEN, E.; KRAUSE-LEMKE, C. A aquisição da Libras por crianças ouvintes filhas de mãe surda num contexto multilíngue. Seminário de Pesquisa do PPE, Universidade Estadual de Maringá, p. 1-19, 2013.

Recebido em: 20/04/2020. Aceito em: 18/06/2020. 